Cahiers $d u$ MONDE RUSSE

\section{Cahiers du monde russe}

Russie - Empire russe - Union soviétique et États indépendants

$46 / 4 \mid 2005$

L'invention d'une politique humanitaire

\title{
Dietmar Neutatz, Die Moskauer Metro
}

\section{Gábor T. Rittersporn}

\section{OpenEdition \\ Journals}

Édition électronique

URL : https://journals.openedition.org/monderusse/6588

DOI : $10.4000 /$ monderusse. 6588

ISSN : $1777-5388$

\section{Éditeur}

Éditions de l'EHESS

\section{Édition imprimée}

Date de publication : 1 décembre 2005

Pagination : 894-896

ISBN : 2-7132-2057-2

ISSN : $1252-6576$

\section{Référence électronique}

Gábor T. Rittersporn, «Dietmar Neutatz, Die Moskauer Metro », Cahiers du monde russe [En ligne], 46/4 | 2005, mis en ligne le 29 juin 2009, consulté le 02 septembre 2022. URL : http://

journals.openedition.org/monderusse/6588; DOI : https://doi.org/10.4000/monderusse.6588

Ce document a été généré automatiquement le 2 septembre 2022

Tous droits réservés 


\title{
Dietmar Neutatz, Die Moskauer Metro
}

\author{
Gábor T. Rittersporn
}

\section{RÉFÉRENCE}

Dietmar NEUTATZ, Die Moskauer Metro. Von den ersten Plänen bis zur

Großbaustelle des Stalinismus (1897-1935). Cologne : Böhlau, 2001, XVI-678 p.

(Beiträge zur Geschichte Osteuropas, 33)

1 L'histoire ouvrière de la Russie prérévolutionnaire et de l'URSS ne se porte pas bien. On peut se demander si elle n'est pas victime du succès qu'elle a connu dans les années 1970 et 1980. À bien des égards, elle se focalisait alors sur une classe que nombre d'historiens voyaient comme révolutionnaire avant les bouleversements de 1917 et sur ce que cette classe était devenue dans la société soviétique. Il s'agissait d'étudier une catégorie sociale qui n'a pas confirmé l'espoir qu'elle deviendrait le moteur d'une société égalitaire et autogestionnaire. Ces travaux n'étaient pas nécessairement fondés sur des présupposés marxistes, mais les auteurs partageaient la conviction que la stratification sociale et les conflits qui s'ensuivent sont des données fondamentales et que les masses radicales sont à même d'influencer notablement le cours de l'histoire.

2 Les historiens de la période soviétique s'intéressent peu désormais à la révolution et n'attendent plus grand-chose des masses. La division de la société en élites et couches populaires ne suscite plus l'intérêt. Adieu les discussions stériles des années 1960, où les soviétologues cherchaient à déterminer si l'URSS était devenue, ou non, une société de classes. De nos jours, les chercheurs n'oublient pas les tensions entre privilégiés et laissés-pour-compte, mais c'est avant tout au sein du monde rural qu'ils les analysent. Dans d'autres sphères, ils hésitent à leur attribuer un rôle décisif dans la formation d'espaces sociaux et de modèles culturels. Il y a cependant des paradigmes des années 1960 qui connaissent une seconde jeunesse. L'un d'entre eux est l'adaptation irrésistible des individus au régime soviétique, que les antagonismes entre groupes n'entament 
guère. Mais c'est plutôt l'assimilation des normes soviétiques que l'on étudie actuellement, en s'éloignant de l'hypothèse que les milieux populaires sont capables de produire leurs propres valeurs.

3 L'ouvrage de Dietmar Neutatz est aujourd'hui l'une des rares publications dans laquelle les ouvriers soviétiques occupent une place éminente. Cette monographie s'inscrit dans les nouvelles tendances de l'historiographie. Elle décrit la construction du métro de Moscou - réalisation éminemment soviétique -, qui est l'un des laboratoires les plus intéressants pour observer les travailleurs soviétiques des années 1930. Il s'agit de la première histoire des efforts pour réaliser l'un des fleurons de la future capitale du prolétariat international - ou de ce qui était censé le devenir. Le récit s'arrête en 1935, à l'ouverture de la première ligne. C'est bien l'époque héroïque du grand projet et son univers social qui sont au centre du travail.

4 Neutatz fait plus qu'étudier les ouvriers, il remonte aux origines du projet de doter Moscou de transports souterrains. On a tendance à attribuer le dessein du métro au régime soviétique. Or la première initiative date de 1897. Deux plans étaient en compétition en 1902, mais la municipalité était d'avis que le réseau de tramways existant satisfaisait les besoins. À la veille de la Première Guerre mondiale, l'accroissement de la population et du nombre des passagers remit l'idée du métro à l'ordre du jour. Rien ne montre mieux la continuité entre les projets d'avant-guerre et ceux élaborés à partir des années 1920 que les tracés où sont reprises les lignes prévues avant 1917. Un nombre important des ingénieurs requis pour les travaux avaient été formés sous l'Ancien Régime et à l'étranger. Certains d'entre eux avaient participé à la construction du métro à Berlin ou à Paris. D'autres, accusés de sabotage, se trouvaient en prison en 1931 quand le Politbjuro ordonna la construction de l'ouvrage.

5 Les travaux commencèrent la même année, mais ce n'est qu'en 1933 que la direction du parti accepta le projet technologique définitif pour les différentes tranches. Il fallut alors modifier la profondeur de plusieurs tunnels. Les difficultés étaient aggravées par des inondations souterraines et des conditions géologiques inattendues.

6 Neutatz retrace fidèlement ces péripéties. Il décrit la lutte acharnée qu'ouvriers et ingénieurs devaient livrer pour s'acquitter de leur tâche. Leurs exploits frôlaient souvent les limites des capacités humaines. Si l'enthousiasme bolchevik joua un certain rôle, d'autres facteurs furent tout aussi importants. L'auteur souligne le dynamisme que quelques travailleurs de choc pouvaient générer dans les brigades, ainsi que l'atmosphère spécifique du chantier, l'ambiance d'état de guerre virtuel que le rythme effréné de la construction suscitait. Le parti avait fixé des délais très courts. Or l'équipement laissait à désirer : si les machines ultramodernes mises en œuvre étaient efficaces, c'est en maniant la pioche et la pelle que le gros du travail fut accompli.

7 Ces conditions expliquent le pourcentage élevé de départs volontaires. La pauvreté des baraques où les ouvriers étaient logés contribuait à maintenir le nombre de démissions à un niveau qui, néanmoins, ne dépassait guère la moyenne dans le bâtiment. Les membres du Komsomol et du parti étaient tout aussi prêts à abandonner le chantier que le reste de la main-d'œuvre. Alors que le projet était patronné par cette organisation de la jeunesse, ses membres rechignaient à se faire embaucher et constituaient une minorité du personnel.

8 Neutatz brosse un portrait nuancé des constructeurs. Il les divise en piliers du régime et en travailleurs moyens, mais évite soigneusement d'appliquer ces catégories d'une manière réductrice. L'auteur n'omet pas de mentionner le faible niveau de discipline des 
ouvriers. Il considère qu'il fallait dans une certaine mesure le tolérer en tant que soupape de sécurité permettant de canaliser le mécontentement, ce qui contribuait ainsi à la stabilisation du régime. Neutatz s'intéresse avant tout à ce qui intégrait les masses dans le système, si bien qu'il ne s'attarde pas sur les travailleurs que l'État-parti ne réussissait pas à intégrer.

9 La direction du parti de la capitale fit tout pour stimuler l'équipe de construction et tenta d'améliorer les conditions de vie et de travail. Les chefs du parti ne prenaient la pelle que devant les caméras mais ils étaient littéralement à pied d'œuvre, visitaient le chantier tous les jours et tentaient de résoudre nombre de problèmes. Lazar' Kaganovič, qui avait été à la tête de l'organisation de Moscou, continua de s'occuper de tous les détails même quand il fut muté à un autre poste. On le voyait souvent descendre dans les puits. La présence quotidienne des dirigeants n'était sans doute pas sans influence sur les fonctionnaires du parti qui devaient contrôler l'exécution des plans, ainsi que sur les autres cadres, bolcheviks ou non. Parmi les ingénieurs, certains n'étaient pas des inconditionnels du régime mais leur réserves par rapport à l'État-parti n'empêchaient pas un engagement sincère dans le projet.

10 Neutatz indique que le métro était un chantier privilégié qui n'avait pas d'équivalent dans le pays. Bien que l'approvisionnement en matériaux et en machines ait pu s'interrompre de temps à autre, et malgré mille problèmes qui restaient insolubles dans toute l'industrie, les autorités étaient incomparablement plus attentives aux besoins de cette construction pilote qu'à ceux d'autres entreprises. D'où le fait que l'encadrement des ouvriers y était certainement plus efficace et leur adaptation au système sans doute plus réussie qu'ailleurs. Là, le régime pouvait faire la démonstration de ses capacités à mobiliser, à contrôler et à motiver les citoyens pour accomplir une tâche extraordinaire. Cependant, il fallait pour cela créer des conditions très favorables, ce que l'État-parti n'était pas à même de faire dans le reste de l'URSS.

11 La construction du métro s'approcha peut-être de l'idéal que les bolcheviks voulaient réaliser. Elle n'en montre pas moins l'écart qui subsistait entre leurs idéaux et le quotidien. 